\title{
Hoping for something new
}

\section{A ESPERAnÇA do nOVO}

Florentino CARdoso ${ }^{1}$

'President of the Brazilian Medical Association

A new light was lit with the change of government. Will this flame be kept burning, illuminating a better future? We shall soon see. Things cannot continue as they are, failing to meet the expectations of the vast majority of Brazilians. Brazil's script must be revised, especially with better education and health care for our population.

We lived a time of "more" without any concern for quality - more doctors, more specialists; these are examples of the folly of a government drenched in corruption, which led the country to bankruptcy. We need more doctors in certain specialties and in some places because doctors are heavily concentrated in capitals and larger cities. What incentives do medical doctors have to work in places of difficult access and provision? What are the working conditions for them? The population, even the poor and needy, has no doubt that health care in Brazil is chaotic.

Medical specialties were also threatened when the previous government sponsored the "more" program, with zero quality, a lure to the people. They tried to "make specialists" out of those who undertook low-quality courses approved by the Ministry of Education, in many cases with reduced hours, taught through distance education and without practical activities. These courses are traps designed for people to waste money; they threaten proper medical training and endanger health care. This cannot thrive, and urgent measures need to be adopted by the new government.

Health care is bad, even in sectors of supplementary health and education. The authorities continue to give their approval for the opening of medical schools that do not present the proper conditions to educate good doctors. It is the race of deputies and senators "sponsoring" medical schools in cities devoid of good health conditions, where there is a lack of professionals in various specialties. They say we stand for the training of medical experts. We do! The unwary who say this are talking about something they do not know; for example, they do not know that family and community physicians are medical specialists. "One can only recognize what one knows" is an always current saying.

And clinical research in Brazil crawls trailing other countries that invest in research (United States, several European countries, Japan, South Korea, and more). We know that research leads to development, resources, and opportunities for both researchers and the public. How many Brazilians miss opportunities to participate in new and better treatments for different health problems due to the incompetence and sluggishness of our bureaucratic CEP-Conep-Anvisa system? The National Health Surveillance Agency (Anvisa) has shown signs of improvement and we hope that it will help to "untie the knot," so we can create a new reality.

In this scenario (care, teaching, and research in health), we can imagine the situation of health care management, another mainstay of the area. Why continue to choose managers who are committed to politics and elections at the expense of merit, focus on goals, results and outcomes? Why don't we move further in the work grounded in strong scientific evidence? When a patient needs treatment, we should treat them at the right time, in the right place and with the right professional. The invasion of other health professionals who have not had adequate training to perform certain activities is frightening, and puts people's lives at risk. How many deaths have occurred in esthetic procedures performed by non-specialists?

Our uncompromising defense of merit, competence, and the truth is intended to protect the population, because we take care of our greatest asset: health. And in order to have a better future, we must think beyond diagnosis and treatment (do not care much for rehabilitation). Let us work to improve early diagnosis, focusing on prevention, on health promotion, and especially on health education, which can truly change the sad current scenario for the next generations. Too bad that such immeasurable politicization only sees the short term (term of office and re-election). We must see and work for Brazil's future, planning the next 5, 10, 20 years, that is, the new generations.

What should we expect from this new government? Show its good intentions with structural and major course changes, thinking about the people, not about a party or a government. Enough!

We are ready to help without any political ideology, seeking quality in our services. And if the high ranks do not meet our expectations, let us pray for better choices in the upcoming elections. Health is our greatest asset and we deserve respect. 